\title{
Rekost-M Bone Replacement Implants Based on 3D Modeling for Closing Post-Craniotomy Skull Defects: Pre-Clinical and Clinical Studies
}

\author{
DOI: $10.17691 / \mathrm{stm} 2018.10 .3 .11$
}

Received April 19, 2018

Yu.N. Kolmogorov, PhD, Production Manager ${ }^{1}$;

I.V. Uspensky, Chief Expert ${ }^{1}$;

A.N. Maslov, Bone Replacement Materials Production Manager ${ }^{1}$;

A.E. Novikov, Assistant, Department of Traumatology and Orthopedics;

D.A. Tarasov, MD, Neurosurgeon ${ }^{3}$;

N.L. Myachin, MD, Head of the Department of Neurosurgery3;

A.Yu. Goncharov, MD, Neurosurgeon ${ }^{3}$;

A.S. Korzun, MD, Neurosurgeon;

T.F. Latypov, MD, Head of the Department of Neurosurgery4;

D.A. Yadykov, MD, Neurosurgeon ${ }^{4}$;

I.V. Balyazin-Parfenov, MD, DSc, Associate Professor, Department of Nervous Diseases and Neurosurgery ${ }^{5}$

${ }^{1}$ Icon Lab GmbH, 1 Barrikad St., Nizhny Novgorod, 603003, Russia;

2Privolzhsky Research Medical University, 10/1 Minin and Pozharsky Square, Nizhny Novgorod, 603005, Russia;

${ }^{3}$ V.A. Baranov Hospital, 3 Pirogova St., Petrozavodsk, Republic of Karelia, 185019, Russia;

${ }^{4}$ Emergency Hospital, 18 Naberezhnochelninsky Prospect, Naberezhnye Chelny, Republic of Tatarstan,

423803, Russia;

${ }^{5}$ Rostov State Medical University, 29 Per. Nakhichevan, Rostov-on-Don, 344022, Russia

The aim of the study was to test an innovative implant made of the urethane bone-replacing material Rekost-M using 3D technologies for customized reconstruction of post-craniotomy skull defects.

Materials and Methods. To study the properties of the bone replacement material Rekost-M, physical, mechanical and toxicological tests, as well as preclinical studies on fibroblasts cultures and lab animals (rabbits) were carried out. Clinical evaluation of the developed implant was conducted within a multicenter trial.

Results. The replacement of post-craniotomy skull defects with implants made of the bone replacement material Rekost-M represents a reliable method of cranioplasty. Using 3D technology allows for modeling of individual implants of any complexity.

Key words: bone replacement materials; Rekost-M; closure of skull defects; 3D modeling.

\section{Introduction}

For the purpose of cranial defects reconstruction, the following implant materials are currently available in the world market: synthetic materials (protacryl, palakos) [1]; automaterials (autobone) [2, 3]; ceramic implants (corundum ceramics); metals (titanium and its alloys) $[4,5]$; hydroxyapatite.
Biocompatibility is a major requirement that determines the choice of the material. There are indications that polymethyl methacrylate and other methacrylic acid polymers lack the required biocompatibility, which often makes them toxic to surrounding tissues and leads to an unacceptably high number of complications. The process of protacryl polymerization takes more than $1.5 \mathrm{~h}$; this reaction is

Corresponding author: Igor V. Uspensky, e-mail: i.uspensky@iconlab.ru 


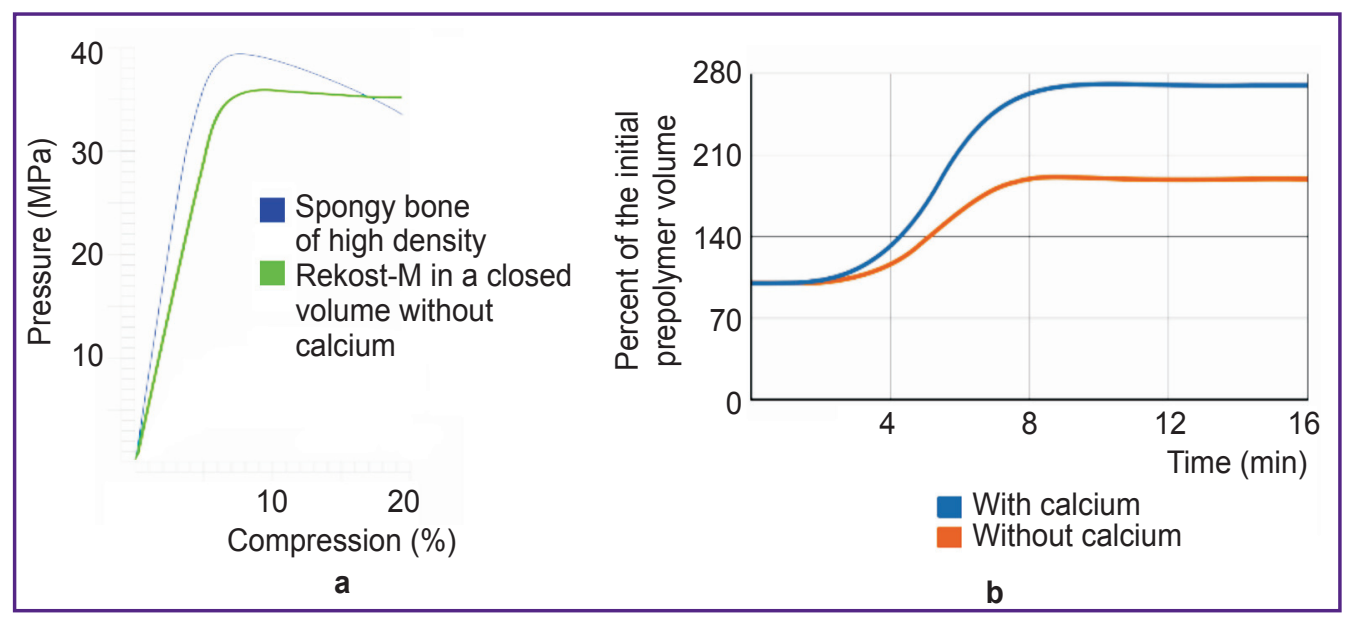

Figure 1. Physical and mechanical properties of the Rekost-M material:

(a) strength; (b) expansion

associated with considerable heating and toxic gases release.

The use of corundum ceramics can cause $(5 \%$ of cases) with trophic abnormalities of soft tissues; ultimately, the device should be removed from the body.

Some authors [3] believe that autologous bone materials, in particular the autobone, are most appropriate for correcting bone defects. In the absence of an autologous bone, the preferred material is the allobone, which stimulates the processes of bone formation from the recipient tissues and serves as a source of bone regeneration.

However, autoplastic materials are not entirely harmless: they can cause inflammatory complications or can be resorbed. As reported, titanium and its alloys showed sufficient biocompatibility and a minimal number of complications [4, 5].

Yet, biocompatibility is not the only challenge to a surgeon working with a bone defect. There is also a problem of restoring the natural shape of the skull, especially if the defect occurred in a complex anatomical zone. Using a titanium mesh to model and create a complex configuration is quite problematic.

Another material, hydroxyapatite cement, is also used to close defects of the skull, but the size of the defect should not exceed $30 \mathrm{~cm}^{2}$. For large defects, hydroxyapatite must be reinforced with a titanium mesh to improve the physical \& mechanical properties. An additional factor - its high (in dozens of times) cost compared to other materials - should also be noted.

The above arguments provide a rationale for searching for novel materials and methods to improve the procedure of closing of bone defects [6, 7].

Since 2011, Icon Lab GmbH (Russia) has been developing materials able to close bone defects during reconstructive and plastic operations, to produce bone implants, and to replace various bone defects. In 2014, a new bone replacement material Rekost and its solidified version Rekost-M, containing an osteoconductive and biocompatible polymer, were synthesized [8]. In those, a polyurethane polymer serves as the osteoconductive and biocompatible component; that is produced from polyoxypropylene glycol (with an average molecular weight of 1000), 4,4'-diisocyanatodiphenylmethane, and glycerin. On July 3, 2014, the Federal Health Service issued a registration certificate for medical product No.P3H 2014/1646 "Rekost and Rekost-M polymer bone replacement material for reconstructive surgery".

Physical and mechanical tests of the material were carried out using Zwick/Roell Z100 equipment (Germany).

The resulting material has pores of $50-400 \mu \mathrm{m}$ in size. The compression strength is $25-35 \mathrm{MPa}$, the adhesion to metal and bone is $60-65 \mathrm{~kg} / \mathrm{cm}^{2}$. It has been found that the physical and mechanical properties of Rekost-M (strength and expansion) are close to the native bone structure and can be adjusted to a specific clinical task (Figure 1).

Until the moment of full hardening, this bone replacement material is plastic and flexible, which allows for modeling and gluing. On the base of the 3D technology, the material can be shaped into plates, cylinders and other templates to fit individual shape of the implants.

\section{Preclinical and Clinical Tests}

Preclinical tests of bone replacement material Rekost-M were carried out at the Nizhny Novgorod Research Institute of Traumatology and Orthopedics (Russia) according to the ISO GOST 10993 standard. Two series of experiments were run to study the effect of this material on adhesion, proliferation and fibronectin synthesis in human dermal fibroblasts in vitro. To this end, a bone replacement material was prepared in a Petri dish under sterile conditions as follows: $0.7 \mathrm{ml}$ of 
Table 1

Cell density of a fibroblast culture in the presence of the Rekost-M bone replacement material (cells $\left./ \mathrm{cm}^{2}\right)$

\begin{tabular}{lcccccccccc}
\hline & \multicolumn{3}{c}{ Experiment 1 (line 1) } & \multicolumn{3}{c}{ Experiment 2 (line 2) } & \multicolumn{3}{c}{ Experiment 3 (line 3) } \\
\cline { 2 - 11 } Groups & \multicolumn{9}{c}{ Time of growth (h) } \\
& 48 & 72 & 96 & 48 & 72 & 96 & 48 & 72 & 96 \\
\hline Control & $26 \cdot 10^{3}$ & $39 \cdot 10^{3}$ & $43 \cdot 10^{3}$ & $31 \cdot 10^{3}$ & $47.6 \cdot 10^{3}$ & $71 \cdot 10^{3}$ & $27 \cdot 10^{3}$ & $36 \cdot 10^{3}$ & $41 \cdot 10^{3}$ \\
\hline Study & $26 \cdot 10^{3}$ & $36.2 \cdot 10^{3}$ & $45 \cdot 10^{3}$ & $36 \cdot 10^{3}$ & $53 \cdot 10^{3}$ & $33 \cdot 10^{3}$ & $29 \cdot 10^{3}$ & $36.2 \cdot 10^{3}$ & $39.8 \cdot 10^{3}$ \\
\hline
\end{tabular}

Table 2

The number of dead cells in a fibroblast culture in the presence of the Rekost-M bone replacement material (\%)

\begin{tabular}{|c|c|c|c|c|c|c|c|c|c|}
\hline \multirow{3}{*}{ Groups } & \multicolumn{3}{|c|}{ Experiment 1 (line 1) } & \multicolumn{3}{|c|}{ Experiment 2 (line 2) } & \multicolumn{3}{|c|}{ Experiment 3 (line 3) } \\
\hline & \multicolumn{9}{|c|}{ Time of growth (h) } \\
\hline & 48 & 72 & 96 & 48 & 72 & 96 & 48 & 72 & 96 \\
\hline Control & 2 & 2 & 2 & 2 & 3 & 1 & 2 & 1 & 2 \\
\hline Study & 2 & 1 & 2 & 2 & 2 & 2 & 1 & 2 & 2 \\
\hline
\end{tabular}

Table 3

The concentration of fibronectin in the medium of a fibroblast culture in the presence of the Rekost-M bone replacement material $(\mathrm{ng} / \mathrm{ml})$

\begin{tabular}{lccccccccc}
\hline & \multicolumn{3}{c}{ Experiment 1 (line 1) } & \multicolumn{3}{c}{ Experiment 2 (line 2) } & \multicolumn{3}{c}{ Experiment 3 (line 3) } \\
\cline { 2 - 12 } Groups & \multicolumn{1}{c}{ Time of growth (h) } \\
& 48 & 72 & 96 & 48 & 72 & 96 & 48 & 72 & 96 \\
\hline Control & 1182 & 1571 & 1553 & 1102 & 1101 & 1281 & 914 & 1261 & 1342 \\
\hline Study & 1251 & 1771 & 1872 & 1231 & 1602 & 1492 & 884 & 1273 & 1241 \\
\hline
\end{tabular}

a polyol with dissolved catalyst was added to $10 \mathrm{ml}$ of the prepolymer. Then, after complete solidification of this mixture, small samples of $0.1 \mathrm{~cm}^{2}$ were placed in special cells measuring $1 \mathrm{~cm}^{2}$ and then added with cultured human fibroblasts at different time points. Regular culture of fibroblasts served as a control.

At the first stage, experiments were carried out using three lines of human dermal fibroblasts with two sets of the bone replacement material.

Table 1 shows changes in cell density per unit area of the culture plate during the culture growth in the presence of the bone replacement material. The initial inoculum concentration was $20 \cdot 10^{3}$ cells $/ \mathrm{ml}$.

Table 2 shows changes in the dead/total cells ratio during the culture growth in the presence of the bone replacement material. The initial inoculum concentration was $20 \cdot 10^{3}$ cells $/ \mathrm{ml}$. The cell viability was determined by vital staining with trypan blue.

Table 3 shows changes in fibronectin $(\mathrm{ng} / \mathrm{ml})$ in the culture medium during the cell growth in the presence of the bone replacement material. The initial inoculum concentration was $20 \cdot 10^{3}$ cells $/ \mathrm{ml}$.

The above experiments demonstrated that the test samples of the bone replacement material did not affect the adhesion, the proliferation or the synthesis of fibronectin in cultured connective tissue cells (fibroblasts).

These experiments indicated that the Rekost-M material was biocompatible and free of cytotoxic effects in vitro.

At the second stage, tests with 12 inbred line rabbits were conducted. The polymer material was implanted into the femur (three implants of $3 \times 5 \mathrm{~mm}$ per animal). Within 12-24 h, the rabbits' condition got normalized. The body temperature was normal, and the animals were active. There were no local inflammatory reactions.

In 12 weeks after the implantation, 7 animals were withdrawn from the experiment. The presented microphotographs of histological preparations (Figure 2) clearly show:

the implanted material was neither encapsulated nor rejected, and there was no fibrous capsule;

newly formed osteoblasts can be seen on the bonematerial interface.

Thus, the animal tests showed no undesirable impact of osseous (intraosseous) implantation on the bone tissues, which supported the claim of biocompatibility and osteoconduction of the novel material.

In a joint project with the GITO-Innovation (Nizhny Novgorod, Russia) [9-11], we have started using the 


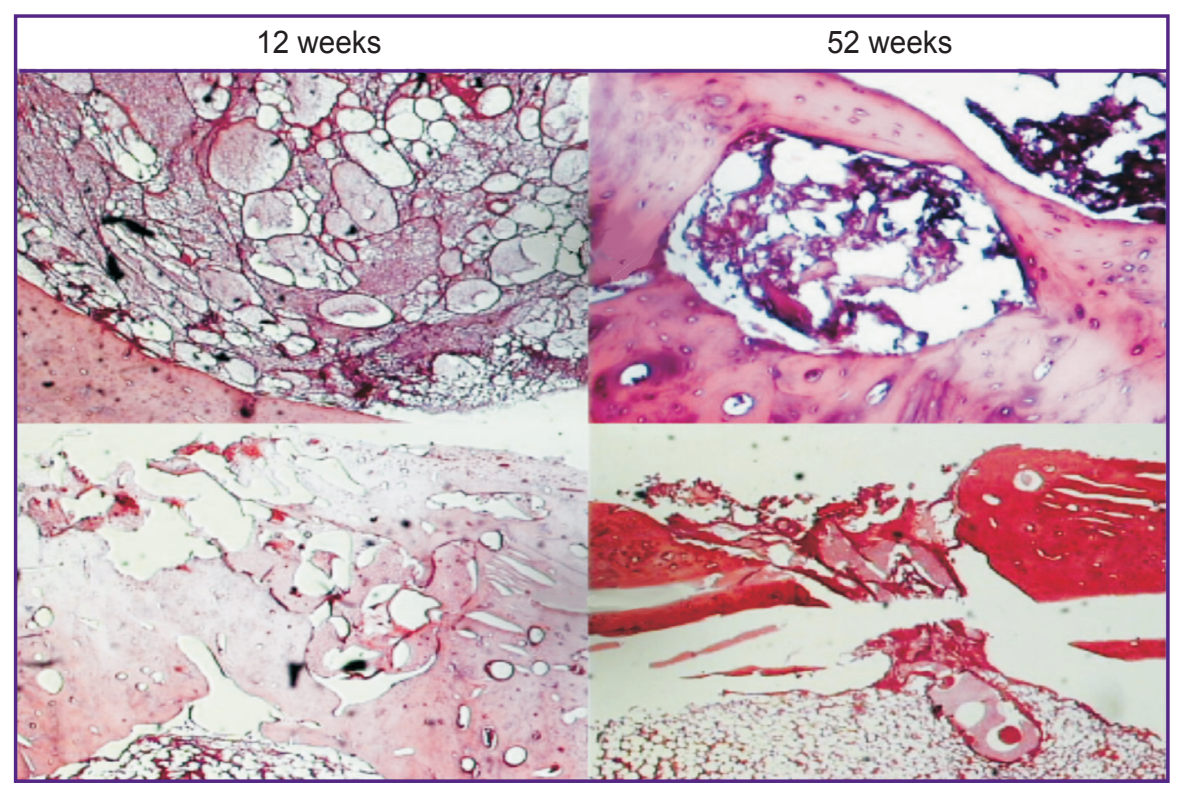

Figure 2. The Rekost-M material in the femur of a rabbit

The defect is made of well-formed bone beams with shaped Haversian canals bone tumor (leukomyosarcoma and osteoma) and 1 patient with a complication of decompressive hemicraniotomy. The dimensions of the defects were: in 7 patients - extensive, in 2 large. The defects were localized as follows: in 6 patients - frontalparietal-temporal, in 1 patient frontal-orbital, in 1 - parietal, and in 1 - frontal. In 1 patient with a frontal-parietal-temporal defect, encephalocele was found. To calculate the size of the cranial defect, each patient underwent a preliminary computed tomography scan with a slice thickness of $1.25 \mathrm{~mm}$ using the bone reconstruction mode.

All patients with posttraumatic defects were operated in the interim period and two patients with cranial vault tumors underwent primary cranioplasty. The implants were fastened with metallic CranioFix clamps. Following the surgery, all patients wore drainage catheters with active vacuum aspiration for the next $48 \mathrm{~h}$.

The study was conducted in accordance with the Helsinki Declaration (2013) and approved by the Ethics Committee of the V.A. Baranov Hospital. An informed consent had been obtained from each patient.

Here we present a few clinical examples related to the use of Rekost-M implants.

\section{Patient F., 39 years old, Petrozavodsk.}

Diagnosis: "postoperative defect of the cranial vault".

History of the disease: the patient suffers from brain aneurysm. On August 14, 2014, underwent surgery following an aneurysm rupture on the left. On August 18, 2014, an extensive decompressive craniotomy was performed because of a brain edema. After the operation, a communicating hydrocephalus developed, and another surgery was undertaken on September 30, 2014, to perform the lumbar-peritoneal shunting. After the surgery, the pronounced neurological deficit persisted: that manifested in right-sided deep hemiparesis - up to the right-arm plegia, aphasia, and impaired vision. On April 24, 2015, the patient underwent ventricular-peritoneal bypass at the rightside Kocher's point. On April 27, 2015 - a shunt revision was performed.

One year after the aneurysm surgery, the patient was electively hospitalized to undergo cranioplasty. She was operated in the Department of neurosurgery where meningolysis, encephalolysis, and evacuation of the brain cysts were performed. The reconstitution of the skull defect was carried out using a customized prosthesis made of the Rekost-M material (Figure 3). 

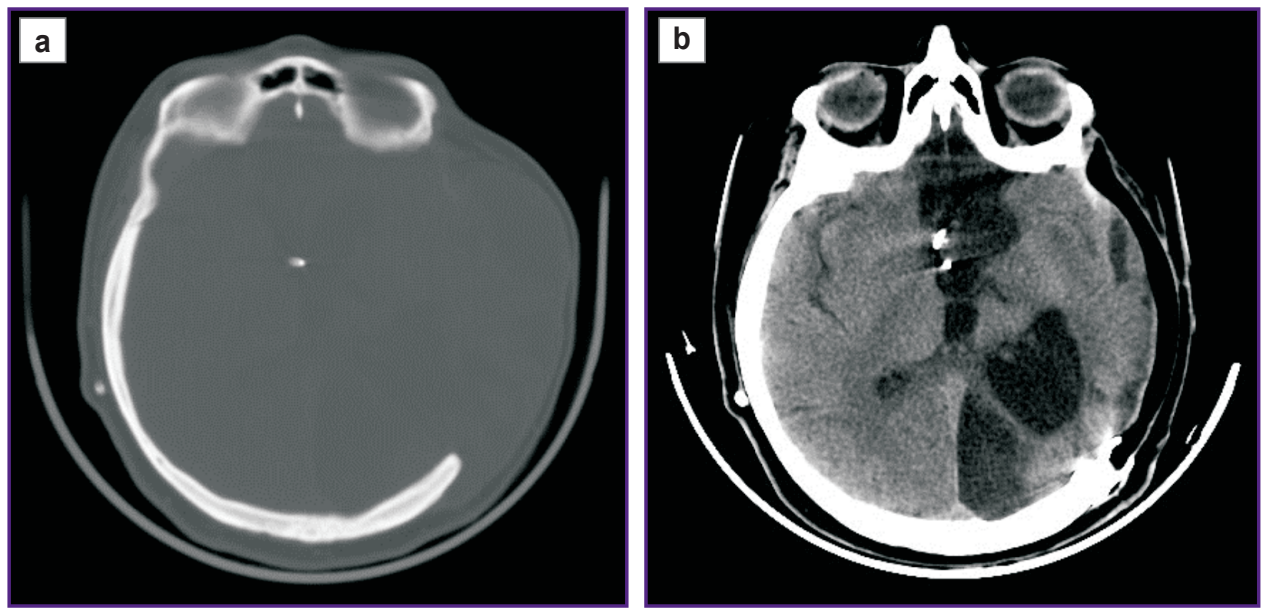

Figure 3. Patient F., 39 years old, the diagnosis: "postoperative defect of the cranial vault" Spiral computed tomography of the brain before (a) and after (b) cranioplasty

Figure 4. Patient M., 34 years old, the diagnosis: "posttraumatic defect of the cranial vault" $3 \mathrm{D}$ reconstruction of the cranial defect based on spiral computed tomography of the brain (a); spiral computed tomography after cranioplasty (b)
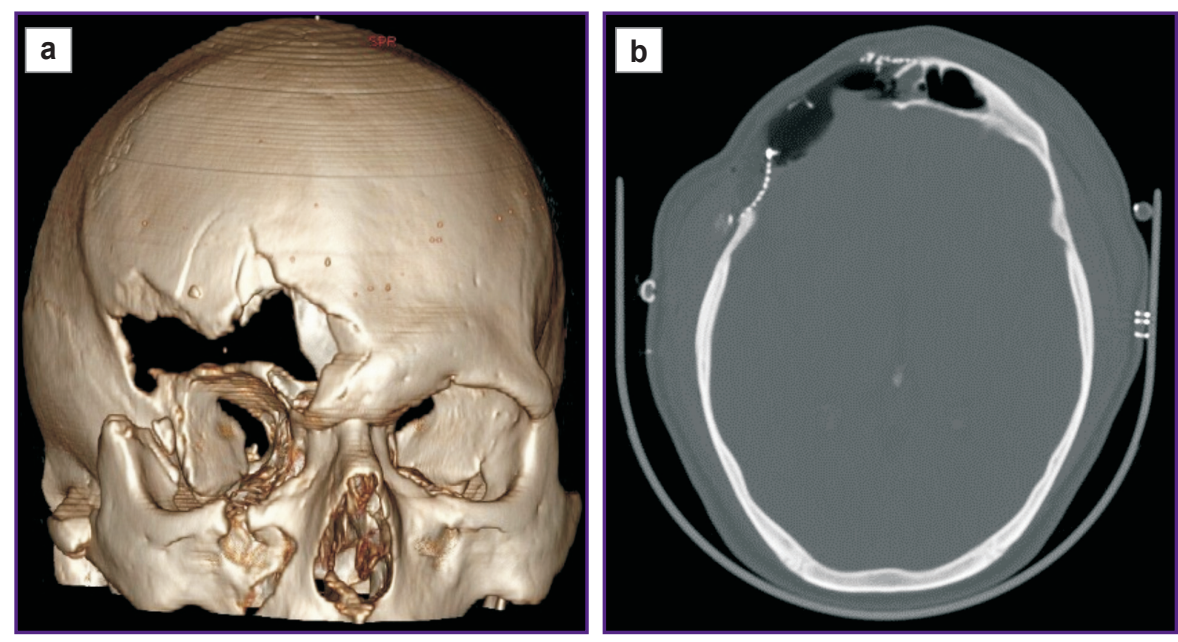

Patient M., 34 years old, Petrozavodsk.

Diagnosis: "posttraumatic defect of the cranial vault".

History of the disease: the trauma resulted from a traffic accident on March 18, 2016; the patient experienced a loss of consciousness. He was hospitalized at the regional hospital with the diagnosis of acute head injury, brain contusion, and an open expression fracture of the frontal bone. Urgent surgical treatment including the removal of bone fragments followed. The postoperative period proceeded with no complications.

Later (on June 22, 2016), the patient was rehospitalized to undergo plastic surgery and close the cranial defect. Cranioplasty was performed using a customized Rekost-M based plastic plate (Figure 4).

Patient R., 52 years old, Naberezhnye Chelny.

Diagnosis: "traumatic brain disease; late recovery period after a severe brain contusion (October 2013). Status after right-side decompressive craniotomy with a removal of an acute subdural hematoma and left-side craniotomy with a removal of an acute epidural hematoma".
History of the disease: in October 2013, as a result of a traffic accident, the patient received a severe cranial injury and brain contusion. He was also diagnosed with acute subdural hematoma on the right and epidural hematoma on the left, dislocation of the median brain structures to the left by $10 \mathrm{~mm}$, and brain edema.

Decompressive craniotomy with a removal of the rightside acute subdural hematoma and the left-side epidural hematoma was performed. The patient then showed a gradual decrease in the cerebral and focal neurological symptoms. In two days, he woke up from a coma. The rough left-sided hemiparesis eased upon 22 days of his hospital stay.

Surgical intervention: on March 14, 2017, bilateral cranioplasty was performed using the Rekost-M polymeric bone replacement material obtained with the help of $3 D$ modeling. The surgery lasted for $90 \mathrm{~min}$; the blood loss was $150 \mathrm{ml}$ and there were no complications. Following meningolysis, the prostheses were fixed with bone sutures. The subcutaneous space was drained with polyvinyl chloride drainage for $24 \mathrm{~h}$. 

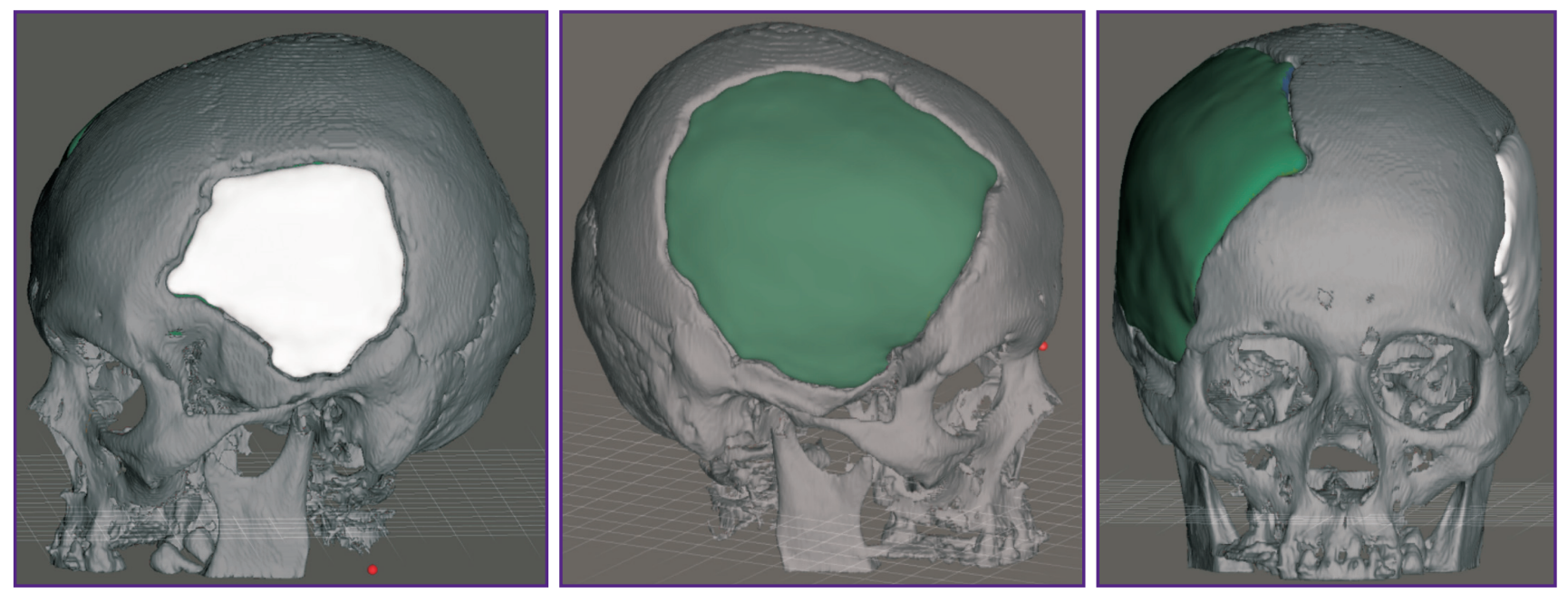

Figure 5. Patient R., 52 years old, the diagnosis: "traumatic brain disease, status after a decompressive bilateral craniotomy"; 3D reconstruction of the skull defects
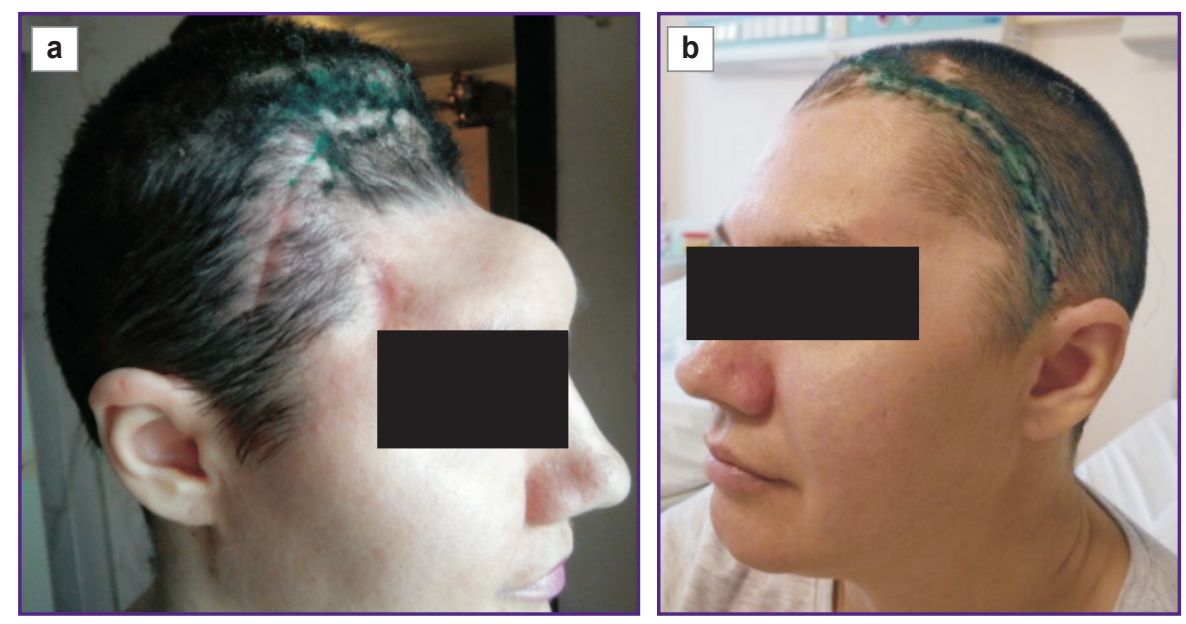

Figure 6. Patient L., 41 years old, the diagnosis: "status after bilateral frontal craniotomy and autobone cranioplasty; bone flap osteomyelitis; status after removal of a bilateral frontal bone flap"

Condition before (a) and after (b) cranioplasty

The postoperative period proceeded smoothly, without complications. The patient was discharged on day 8 (Figure 5).

\section{Patient L., 41 years old, Naberezhnye Chelny.}

Diagnosis: "late recovery period after a non-traumatic subarachnoid hemorrhage; brain aneurysm; status after the open clipping of an anterior connective artery aneurysm on February 5, 2016; status after decompressive bilateral frontal craniotomy on February 6, 2016; status after an autobone-assisted cranioplasty on October 5, 2016; osteomyelitis of the bone flap; status after a removal of the bilateral frontal bone flap on January 11, 2017".

History of the disease: on February 5, 2016, the patient underwent surgery for a rupture of saccular aneurysm in the anterior connective artery. On February 6, 2016, due to intractable intracranial hypertension and cerebral edema, the patient underwent a bilateral frontal decompressive craniotomy (the bone flap was kept stored in the subcutaneous anterior wall of the abdomen). The postoperative period proceeded with a notable decrease in the neurological deficit. In October 2016, an autobone replacement cranioplasty was performed. In January 2017, the bone flap was removed due to osteomyelitis.

Surgical intervention: on August 25, 2017, cranioplasty using a Rekost-M based graft was performed. The operation lasted for $70 \mathrm{~min}$ with a blood loss of $100 \mathrm{ml}$ and without complications. Upon surgery, the preventive antibiotic treatment with $1 \mathrm{~g}$ of cefazolin was initiated. Following meningolysis, the prosthesis was fixed with 8 bone sutures. The subcutaneous space was drained with a polyvinyl chloride catheter for $24 \mathrm{~h}$.

The postoperative period proceeded smoothly, without complications. The patient was discharged on day 7 (Figure 6).

\section{Patient G., 47 years old, Rostov-on-Don.}

Diagnosis: "condition after osteoplastic craniotomy in the right frontal-parietal area conducted due to meningioma; a bone defect in the right frontal-parietal cranial vault".

History of the disease: on May 13, 2015, the patient was operated for meningioma with the intraosseous growth in the right frontal-parietal area. Bone-plastic craniotomy in the right frontal-parietal area supplemented with resection craniotomy was performed. The patient was on a permanent anti-seizure therapy and no seizures were 


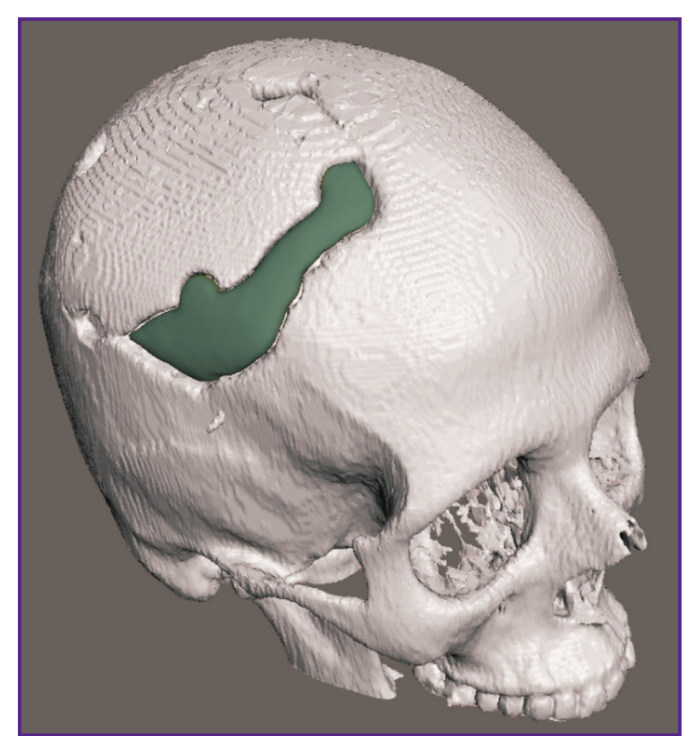

Figure 7. Patient G., 47 years old, the diagnosis: "bone defect of the cranial vault in the right frontal-parietal area after osteoplastic craniotomy for meningioma"; $3 \mathrm{D}$ reconstruction of the skull defects

noted. She was followed up by a local pulmonologist for her bronchial asthma. The patient expressed her concerns about the bone defect measuring $7 \times 3 \times 3 \mathrm{~cm}$ in the right frontal-parietal zone of the cranial vault.

Prior to the cranioplasty, a spiral CT scan was performed on October 15, 2017, followed by 3D modeling and manufacturing of an implant using the Rekost-M biopolymer.

Surgical intervention: on November 22, 2017, the patient was operated to close the bone defect of the cranial vault; allocranioplasty preceded by $3 D$ modeling was performed. A horseshoe-shaped incision was made on the old postoperative scar location. The skin-aponeurotic flap was separated and turned away. The bone defect edges were conditioned with a raspatory and the spikes between the dura mater and the bone were separated. A Rekost-M graft was placed so to completely close the bone defect. The graft is fixed with four CranioFix staples. Hemostasis in the operation wound was established. The skin-aponeurotic flap was put back in place. The wound was closed with nodular sutures.

The patient was discharged on December 2, 2017, upon her recovery (Figure 7).

\section{Conclusion}

The replacement of post-craniotomy skull defects with implants made of the bone replacement material Rekost-M represents a reliable method of cranioplasty. Using 3D technology allows for modeling of individual implants of any complexity.
Financial support. This work was funded by the authors.

Conflict of interest. The authors declare no conflicts of interest.

\section{References}

1. Pedachenko E., Kushchayev S. Modern bone cements for vertebroplasty. Ukraïnskiy neyrokhirurgichniy zhurnal 2001; 4: 24-31.

2. Ginzburg E.R., Starykh E.S. Primenenie konservirovannykh brefotransplantatov $\mathrm{v}$ khirurgii defektov kostey svoda cherepa. V kn.: Materialy V sezda neyrokhirurgov Rossii [The use of preserved brephotransplants in the surgical treatment of bone defects of the cranial vault. In: Proceedings of the V Congress of Neurosurgeons of Russia]. Ufa; 2009; p. 383.

3. Belchenko V.A., Prityko A.G., et al. Kostnye autotransplantaty so svoda cherepa $v$ khirurgii vrozhdennykh i priobretennykh deformatsiy cherepno-litsevoy oblasti. V kn.: Materialy $V$ sezda neyrokhirurgov Rossii [Bone autografts from the cranial vault in the surgery of congenital and acquired deformities of the craniofacial bones. In: Proceedings of the $\mathrm{V}$ Congress of Neurosurgeons of Russia]. Ufa; 2009; p. 381.

4. Leonov S., Kuznetsov D., Evseev M. Opyt ispolzovaniya perforirovannoy titanovoy setki "rotormed" pri plastike defektov cherepa. V kn.: Materialy V sezda neyrokhirurgov Rossii [The use of a perforated titanium mesh Rotormed in the skull defects plastic surgery. In: Proceedings of the $\mathrm{V}$ Congress of Neurosurgeons of Russia]. Ufa; 2009; p. 391.

5. Gevorkov A.V., Davydov E.A. Autokranioplastika s primeneniem dempfernykh fiksatorov iz nikelida titana $\mathrm{s}$ termomekhanicheskoy pamyatyu formy. $\mathrm{V}$ kn.: Materialy $V$ sezda neyrokhirurgov Rossii [Autocranioplasty with the use of damping fasteners made of titanium nickelide with thermomechanical shape memory. In: Proceedings of the V Congress of Neurosurgeons of Russia]. Ufa; 2009; p. 382.

6. Lipatov Yu.S., Kercha Yu.Yu., Sergeeva L.M. Struktura i svoystva poliuretanov [Structure and properties of polyurethanes]. Kiev: Naukova dumka; 1970.

7. Kompozitsionnye materialy na osnove poliuretanov [Composite materials based on polyurethanes]. Pod red. Buist J.M. [Buist J.M. (editor)]. Moscow: Khimiya; 1982.

8. Kolmogorov Yu.N., Uspenskiy I.V., Slinyakov A.Yu. Novikov A.E. Filler material. Patent RU 2518753. 2014.

9. Gorbatov R.O., Niftullaev R.M., Novikov A.E. Precision personalized implants to replace bone defects for treatment of patients with osteoonkology. Sovremennye problemy nauki $i$ obrazovania 2016; 6: 247.

10. Klemenova I.A. Novikov A.V, Gorbatov R.O., Novikov A.E. Individual implants from bone replacing materials for treatment of oncological pathology of bone tissue. Mezhdunarodnyy zhurnal prikladnykh i fundamentalnykh issledovaniy 2017: 9: 30-33.

11. Karyakin N.N., Gorbatov R.O. Novikov A.E., Niftullaev R.M. Surgical treatment of patients with tumors of long bones of upper limbs using tailored 3D printed bone substitute implants. Geniy ortopedii 2017; 23(3): 323-330. 